\title{
PRDM16 in Development and Disease
}

\section{Dennis R Warner, Robert M Greene and Michele Pisano*}

Department of Molecular, Cellular, and Craniofacial Biology University of Louisville Birth Defects Center, Kentucky, USA

*Corresponding author: Michele Pisano, Department of Molecular, Cellular, and Craniofacial Biology, University of Louisville Birth Defects Centre, University of Louisville, Louisville, Kentucky, USA 40292, Tel: 5028521962; Fax: 5028524702; E-mail: Drmikeky@gmail.com

Received date: February 23, 2014, Accepted date: March 28, 2014, Published date: April 10, 2014

Copyright: @ 2014 Warner DR, et al. This is an open-access article distributed under the terms of the Creative Commons Attribution License, which permits unrestricted use, distribution, and reproduction in any medium, provided the original author and source are credited.

\begin{abstract}
PRDM16 is a member of the PRDM family of transcription co-regulators characterized by a PR domain (positive regulatory domain) that is similar to the SET domain found in lysine histone methyltransferases. Most PRDM proteins also contain one or more zinc finger domains that can confer direct DNA binding, in addition to other domains that mediate binding to additional transcription factors and cofactors. PRDM16 was originally identified from studies of $(1 ; 3)(p 36 ; q 21)$-positive leukaemia's but has subsequently been implicated in several developmental processes, including differentiation of muscle cell precursors into brown adipocyte fat cells. Such differentiation, regulated in part by the enzyme tyrosine-protein kinase-2 (Tyk2), has gained recent attention as a means to reduce obesity via manipulating the production of TYK2 and/or PRDM16. In addition, PRDM16 is also involved in hematopoietic stem cell maintenance and craniofacial development. This review focuses on our current understanding of the role of PRDM16 in each of these processes and highlights some of the challenges for future studies.
\end{abstract}

Keywords PRDM family; Craniofacial development; Transcription co-regulators; leukaemia's

\section{PRDM16 Structure and Function}

The PRDM family of proteins currently contains 17 (primates) or 16 (rodents) members which function as transcription co-regulators in tissue differentiation, cell proliferation, and cellular signalling, and are broadly expressed in both embryonic/fetal and adult tissues. Prdm genes are divided into 5 main subfamilies, of which Prdm-2, -3 and 16 constitute one subfamily [1]. The hallmark of all PRDM proteins is the presence of the PR domain, so-named because of its similarity to a domain in PRD1-BF1/BLIMP1 (now known as PRDM1) and RIZ1 (now known as PRDM2) that has been associated with transcriptional repression [2]. The PR domain also has similarities to the SET domain (Su[var]3-9, Enhancer-of-zeste, Trithorax) that is a lysine methyltransferase module that mediates the transfer of a methyl group from $\mathrm{S}$-adenosylmethionine to the $\varepsilon$-amine group of the lysine side chain, leading to gene silencing or activation, depending upon the context [3]. Although not all PRDM proteins exhibit methyltransferase activity, PRDM16 does, and also demonstrates the ability to recruit other methyltransferases $[4,5]$. In addition to the PR domain, most PRDM proteins contain zinc finger domains and may contain one or more protein interaction domains (e.g. C-terminal binding protein [CtBP]-binding domain in PRDM-2, -3-, and -16). PRDM16, located on chromosome $1 \mathrm{p} 36.3$, was first identified as part of a translocation breakpoint in $(1 ; 3)(\mathrm{p} 36 ; \mathrm{q} 21)$-positive leukaemia [6]. A 1275 amino acid PR-domain protein member, PRDM16 is 64\% (nucleotide) and $63 \%$ (amino acid) similar to MDS1/EVI1 (myelodysplasia syndrome 1/ ecotropic viral integration site 1). PRDM16 is also known as MEL1 (MDS1/EVI1-like). It contains 10 zinc finger motifs, separated into two clusters, and a CtBP binding domain (Figure 1). While PRDM16 can directly bind to DNA [7], its role for function is unclear because PRDM16 mutants in the zinc-finger (DNA-binding) domain retain activity in brown adipocyte differentiation [8]. In addition to full-length PRDM16, a splice variant has also been described that is missing the majority of the PR domain because of initiation within exon 4 (the PR domain is encoded by exons 2-5) [7]. Loss of the PR domain may alter the effect of PRDM16 on transforming growth factor- $\beta$ (TGF- $\beta$ ) signalling and increase its oncogenicity [9]. While the structure of PRDM16 has been defined, unravelling the role of PR+ and PR- isoforms remains critical to a complete understanding of PRDM16 function.

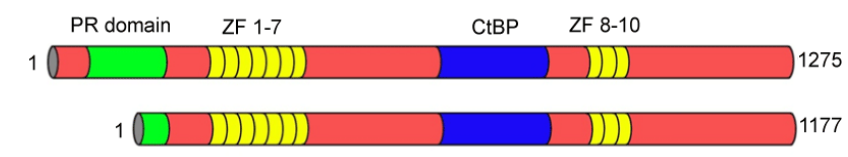

Figure 1: Primary structure of PRDM16

Full-length PRDM16 is a 1275 amino acid, $170 \mathrm{kDa}$ proteins that contains the namesake PR domain (sometimes referred to as the positive regulatory domain). The $\mathrm{PR}$ domain is similar to the SET domain found in PRD1-BF-1 and RIZ1. PRDM16 also contains 10 zinc fingers divided into clusters of 7 and 3, and a CtBP (C-terminal Binding Protein) interaction domain. The PR- splice variant is shown below the full-length version.

\section{PRDM16 and Cancer}

Myelodysplastic syndromes (MDS) are malignancies of hematopoietic stem cells that lead to either single or multiple-lineage blood cell deficiencies with subsequent progression to acute myeloid leukemia (AML), usually with a poor prognosis. MDS can be caused by a translocation $[\mathrm{t}(1 ; 3)(\mathrm{p} 36 ; \mathrm{q} 21)]$ that places the expression of PRDM16 under control of the housekeeping gene, ribophorin 1 (RPN1), leading to ectopic expression [6]. It was later found that the isoform of PRDM16 that lacks the PR domain was overexpressed in 
these translocations [10]. As indicated in the preceding section, this isoform negatively affects TGF $\beta$ signalling and perturbs its growth inhibitory function and may play a role in leukemogenesis in these cases. In addition to aberrant expression of PRDM16 due to $t(1 ; 3)$ (p36;q21) translocations, fusions between runt-related transcription factor 1 (RUNX1) and PRDM16, subsequent to $t(1 ; 21)(p 36 ; q 22)$ translocations, can lead to an inhibition of RUNX1 transactivation of target genes and result in AML [11]. In human T-cell leukaemia virus, type 1 (HTLV-1)-induced adult T-cell leukaemia (ATL), the PRDM16 promoter was shown to be hypomethylated and ectopically expressed in ATL leukemic clones [9]. Further, the PRDM16 isoform lacking the PR domain (MEL1S) was the major splice variant expressed in these cells. Moreover, MEL1S-bearing cell lines were resistant to the growth inhibitory effects of TGF $\beta$ [9], and disruption of the EVI1 or PRDM16 gene, even in the absence of other alterations, was sufficient to cause leukaemia [12].

PRDM16 gene amplifications have been identified in a panel of 48 human osteosarcomas [13]. However, other gene amplifications and deletions were also identified making firm conclusions on the role of PRDM16 in osteosarcoma difficult. More detailed experiments are necessary in order to establish a functional correlation between PRDM16 amplifications and osteosarcoma, or to define whether the full-length, PR-domain containing isoform, or the shorter variant lacking the PR-domain, is involved. Altered expression of PRMD16 has also been demonstrated under conditions of chromosome instability associated with colorectal cancer [14].

In addition to the established role of PRDM16 in myeloid cancers, it was recently shown that this gene is critical for normal hematopoietic stem cell function (cell renewal, differentiation, and apoptosis) [15], suggesting that dysregulation of function can also lead to disorders of haematopoiesis. This role in stem cell maintenance may be a general function of PRDM16 [16].

\section{Other Disorders}

Alteration of PRDM16 structure or expression has been linked to other disease processes. The most common telomeric deletions in humans affects the long arm of chromosome 1 (1p36), with an incidence of 1 in 5000 [17]. The clinical characteristics vary widely, however, two recent studies reported that a minimal deletion that includes the gene for PRDM16 is responsible for the cardiac defects associated with 1 p36 deletion $[18,19]$. The mechanism underlying the cardiac abnormalities is due to decreased proliferation and increased apoptosis of cardiomyocytes leading to abnormal conduction velocities suggesting that PRDM16 is important for these processes [18]. Genome-wide association studies have linked mutations of PRDM16 to migraines; however, its specific role is remains to be elucidated [20-22]. In addition, PRDM16 has been implicated in obesity, metabolic syndrome [23-25], and hypertension [26]. While the mechanism and specific role of PRDM16 in these disorders is not known, these observations support the premise that PRDM16 has quite diverse functions in tissue homeostasis.

\section{PRDM16 and Brown Adipocyte Tissue Differentiation}

The most extensively studied function of PRDM16 is its role in differentiation of precursors into brown adipose tissue (BAT). While white adipose tissue (WAT) is used as a store of energy, the primary function of BAT is to generate body heat in animals or new-borns that do not shiver. It has been demonstrated that PRDM16 is preferentially expressed in BAT where it regulates the expression of peroxisome proliferator-activated receptor gamma, co-activator $1 \alpha$ and $\beta$ (PGC1 $\alpha$ and PGC1 $\beta$ ) and uncoupling protein 1 (UCP1) and the transcriptional activity of both PGC1 $\alpha$ and PGC1 $\beta$ [8]. It was then subsequently demonstrated that PRDM16 was the master regulator of BAT formation by virtue of its interaction with PGC1 $\alpha$ and PGC1 $\beta$ while simultaneously inhibiting the expression of WAT-specific genes through binding to CtBP 1 and 2 [27]. The intense interest in the role of PRDM16 in BAT differentiation is based on its potential to convert WAT to BAT (or "beige fat") as a treatment for obesity. The further detrimental effect of WAT on human health lies partly in the fact that it secretes hormones that lead to insulin resistance (resistin) and increased blood pressure (angiotensinogen), while BAT does not. BAT and WAT do not have the same precursor cells, as was originally thought, BAT arising via PRDM16-dependent transformation of myogenic factor 5 (Myf5)-positive myoblasts [28,29]. Recent studies have revealed a potential upstream regulatory mechanism whereby PRDM16 stimulates the expression of microRNA-193-365 that in turn represses the expression of myogenic genes, and contributes to the expression of the BAT differentiation program [30]. Conversely, microRNA-133 targets PRDM16 in muscle precursor cells to promote myogenesis and thus inhibit BAT differentiation [31,32]. Thus, balanced regulation of myogenesis by specific miRNAs provides tight control of the BAT differentiation program.

PRDM16 was previously shown to be a Smad binding protein that may be important for development $\beta$ of orofacial structures through modulation of the TGF signalling pathway [33]. This interaction was recently emphasized by the demonstration that TGF- $\beta /$ Smad 3 signalling promoted the formation of WAT, whereas loss of Smad3 expression promoted BAT formation [34]. This suggests that PRDM16 may inhibit functionality of Smad3 through direct binding, thereby blocking downstream TGF- $\beta$ signalling. It was recently shown that euchromatic histone-lysine $\mathrm{N}$-methyltransferase 1 (EHMT1) is an essential component of the PRDM16 transcription complex during BAT formation [4]. EHMT1 serves several functions, including stabilization of PRDM16 protein /transactivation of BAT-specific genes and through repressing muscle-specific gene expression by methylating histones in their promoter regions.

\section{PRDM16 and Craniofacial Development}

A role for PRDM16 in development of the secondary palate was first demonstrated by the identification of a N-ethyl-N-nitrosoureainduced missense mutation in the gene for Prdm16 in a mouse mutant (Csp1) that had an isolated cleft of the secondary palate [35]. Further, they identified three human cases with non-syndromic cleft palate that also had Prdm16 missense mutations in their genome suggesting that it may be important for palate development [36]. A bona-fide mouse knockout model, exhibiting a fully penetrant cleft palate in homozygous null fetuses, was subsequently created by a gene-trapping approach. The cleft, however, may be secondary to micrognathia [37].

Nevertheless, a careful study of the underlying molecular mechanisms will be necessary to determine the specific role of PRDM16 in craniofacial development.

Work in other model systems has also demonstrated a role for the PRDM3/5/16, subfamily during craniofacial development. Specifically, loss of either PRDM3, 5, or 16 in zebra fish resulted in orofacial defects, including a truncated Meckel's cartilage and a hypo plastic 
ethmoid plate (the structural homolog in zebrafish to the mammalian secondary palate) [38].

Several studies have examined the role played by PRDM16 in the expression of genes critical for development of a normal secondary palate and mandible. Studies utilizing chromatin immunoprecipitation-microarray analysis (ChIP-Chip) have identified over 100 genes whose promoter was bound by PRDM16 in primary palate mesenchymal cells [39], interestingly; many of the genes bound by PRDM16 were associated with muscle development, consistent with its previously demonstrated function during BAT formation [28]. In addition to genes important for muscle development, many PRDM16-bound genes were associated with chondro- and osteogenesis. Indeed, Prdm16-/- mouse mutants displayed dysregulated expression of genes important for these two processes and a generalized decrease in chondrogenesis, particularly in Meckel's cartilage, possibly explaining the foreshortened mandible in mutant mice [40].

\section{Future Directions}

Since the initial identification of Prdm16 in 2000, there has been noteworthy progress in defining its role in BAT differentiation as well as

craniofacial development. The widespread expression of Prdm16 in developing tissues (brain, lung, liver, gut, and eye) [41] suggests multiple functions for this gene beyond what has been currently reported. Although upstream regulators and downstream targets of PRDM16 have been identified in several cell types, these will likely be tissue specific, and based on its complex domain structure, will depend on other protein binding partners. Identification of these binding proteins will be essential for understanding tissue-specific function.

Because there are two isoforms of PRDM16, one with the PR domain and one without, with potentially opposing functions, clarification of tissue-specific function will require, among other things, determination of tissue distribution. The possibility of redundancy with other subfamily members (PRDM3 and PRDM5) will likely be revealed by overlapping tissue expression.

In conclusion, PRDM16 is a large, widely expressed, complex protein with the ability to bind DNA, methylate histones, and bind numerous other transcription factors. A functional role has been associated with a number of human diseases and several developmental processes in mice. Future studies of PRDM16 should place emphasis on defining its specific role in targeted reduction of obesity. Modulation of PRDM16 expression as well as the expression of other factors important for BAT formation, such as TYK2 and STAT3 holds promise for combating this condition [42]. A comprehensive database of single-nucleotide polymorphisms will be a valuable resource to assess risks and develop tailored therapies for many of the diseases and disorders described in this review. Investigations focused on the developmental role for PRDM family members will be valuable in elucidating specific functional linkages during, for example, and as recent studies suggest, development of the cardiovascular system [43], regulation of stem cells [44,45], cell cycle modulation [46], and osteogenesis [47].

\section{Acknowledgements}

The authors wish to acknowledge financial support from the National Institutes of Health (grants DE018215, HD053509 and P20 GM103453 from the COBRE program of the NIGMS).

\section{References}

1. Fumasoni I, Meani N, Rambaldi D, Scafetta G, Alcalay M, et al. (2007) Family expansion and gene rearrangements contributed to the functional specialization of PRDM genes in vertebrates. BMC Evol Biol 7: 187.

2. Xie M, Shao G, Buyse IM, Huang S (1997) Transcriptional repression mediated by the PR domain zinc finger gene RIZ. J Biol Chem 272: $26360-26366$

3. Binda O (2013) On your histone mark, SET, methylate! Epigenetics 8: 457-463.

4. Ohno H, Shinoda K, Ohyama K, Sharp LZ, Kajimura S (2013) EHMT1 controls brown adipose cell fate and thermogenesis through the PRDM16 complex. Nature 504: 163-167.

5. Pinheiro I, Margueron R, Shukeir N, Eisold M, Fritzsch C, et al. (2012) Prdm3 and Prdm16 are H3K9mel methyltransferases required for mammalian heterochromatin integrity. Cell 150: 948-960.

6. Mochizuki N, Shimizu S, Nagasawa T, Tanaka H, Taniwaki M, et al. (2000) A novel gene, MEL1, mapped to $1 \mathrm{p} 36.3$ is highly homologous to the MDS1/EVI1 gene and is transcriptionally activated in $t(1 ; 3)$ (p36;q21)-positive leukemia cells. Blood 96: 3209-3214.

7. Nishikata I, Sasaki H, Iga M, Tateno Y, Imayoshi S, et al. (2003) A novel EVI1 gene family, MEL1, lacking a PR domain (MEL1S) is expressed mainly in $\mathrm{t}(1 ; 3)$ (p36;q21)-positive AML and blocks G-CSF-induced myeloid differentiation. Blood 102: 3323-3332.

8. Seale P, Kajimura S, Yang W, Chin S, Rohas LM, et al. (2007) Transcriptional control of brown fat determination by PRDM16. Cell Metab 6: 38-54.

9. Yoshida M, Nosaka K, Yasunaga J, Nishikata I, Morishita K, et al. (2004) Aberrant expression of the MEL1S gene identified in association with hypomethylation in adult T-cell leukemia cells. Blood 103: 2753-2760.

10. Xiao Z, Zhang M, Liu X, Zhang Y, Yang L, et al. (2006) MEL1S, not MEL1, is overexpressed in myelodysplastic syndromes patients with $\mathrm{t}(1 ; 3)(\mathrm{p} 36 ; \mathrm{q} 21)$. Leuk Res 30: 332-334.

11. Sakai I, Tamura T, Narumi H, Uchida N, Yakushijin Y, et al. (2005) Novel RUNX1-PRDM16 fusion transcripts in a patient with acute myeloid leukemia showing $\mathrm{t}(1 ; 21)(\mathrm{p} 36 ; \mathrm{q} 22)$. Genes Chromosomes Cancer 44: 265-270.

12. Modlich U, Schambach A, Brugman MH, Wicke DC, Knoess S, et al (2008) Leukemia induction after a single retroviral vector insertion in Evil or Prdm16. Leukemia 22: 1519-1528.

13. Man TK, Lu XY, Jaeweon K, Perlaky L, Harris CP, et al. (2004) Genomewide array comparative genomic hybridization analysis reveals distinct amplifications in osteosarcoma. BMC Cancer 4: 45.

14. Burghel GJ, Lin WY, Whitehouse H, Brock I, Hammond D, et al. (2013) Identification of candidate driver genes in common focal chromosomal aberrations of microsatellite stable colorectal cancer. PLoS One 8: e83859.

15. Aguilo F, Avagyan S, Labar A, Sevilla A, Lee DF, et al. (2011) Prdm16 is a physiologic regulator of hematopoietic stem cells. Blood 117: 5057-5066.

16. Chuikov S, Levi BP, Smith ML, Morrison SJ (2010) Prdm16 promotes stem cell maintenance in multiple tissues, partly by regulating oxidative stress. Nat Cell Biol 12: 999-1006.

17. Heilstedt HA, Ballif BC, Howard LA, Kashork CD, Shaffer LG (2003) Population data suggest that deletions of $1 \mathrm{p} 36$ are a relatively common chromosome abnormality. Clin Genet 64: 310-316.

18. Arndt AK, Schafer S, Drenckhahn JD, Sabeh MK, Plovie ER, et al. (2013) Fine mapping of the $1 \mathrm{p} 36$ deletion syndrome identifies mutation of PRDM16 as a cause of cardiomyopathy. Am J Hum Genet 93: 67-77.

19. Zaveri HP, Beck TF, Hernández-García A, Shelly KE, Montgomery T, et al. (2014) Identification of critical regions and candidate genes for cardiovascular malformations and cardiomyopathy associated with deletions of chromosome 1p36. PLoS One 9: e85600.

20. Schürks M (2012) Genetics of migraine in the age of genome-wide association studies. J Headache Pain 13: 1-9. 
21. Ghosh J, Pradhan S, Mittal B (2013) Genome-wide-associated variants in migraine susceptibility: a replication study from North India. Headache 53: $1583-1594$.

22. Chasman DI, Schürks M, Anttila V, de Vries B, Schminke U, et al. (2011) Genome-wide association study reveals three susceptibility loci for common migraine in the general population. Nat Genet 43: 695-698.

23. Park YM, Province MA, Gao X, Feitosa M, Wu J, et al. (2009) Longitudinal trends in the association of metabolic syndrome with $550 \mathrm{k}$ single-nucleotide polymorphisms in the Framingham Heart Study. BMC Proc 3 Suppl 7: S116.

24. Zhang JH, Li NF, Yan ZT, Zhang de L, Wang HM, et al. (2012) Association of genetic variations of PRDM16 with metabolic syndrome in a general Xinjiang Uygur population. Endocrine 41: 539-541.

25. Yue H, He JW, Ke YH, Zhang H, Wang C, et al. (2013) Association of single nucleotide polymorphism Rs2236518 in PRDM16 gene with BMI in Chinese males. Acta Pharmacol Sin 34: 710-716.

26. Li NF, Wang HM, Bi YW, Zhou L, Yao XG, et al. (2013) [Association study of PRDM16 gene polymorphisms with essential hypertension in Xinjiang Uygur population]. Zhonghua Yi Xue Yi Chuan Xue Za Zhi 30: 716-720.

27. Kajimura S, Seale P, Tomaru T, Erdjument-Bromage H, Cooper MP, et al. (2008) Regulation of the brown and white fat gene programs through a PRDM16/CtBP transcriptional complex. Genes Dev 22: 1397-1409.

28. Seale P, Bjork B, Yang W, Kajimura S, Chin S, et al. (2008) PRDM16 controls a brown fat/skeletal muscle switch. Nature 454: 961-967.

29. Kajimura S, Seale P, Kubota K, Lunsford E, Frangioni JV, et al. (2009) Initiation of myoblast to brown fat switch by a PRDM16-C/EBP-beta transcriptional complex. Nature 460: 1154-1158.

30. Sun L, Xie H, Mori MA, Alexander R, Yuan B, et al. (2011) Mir193b-365 is essential for brown fat differentiation. Nat Cell Biol 13: 958-965.

31. Trajkovski M, Ahmed K, Esau CC, Stoffel M (2012) MyomiR-133 regulates brown fat differentiation through Prdm16. Nat Cell Biol 14 1330-1335.

32. Yin H, Pasut A, Soleimani VD, Bentzinger CF, Antoun G, et al. (2013) MicroRNA-133 controls brown adipose determination in skeletal muscle satellite cells by targeting Prdm16. Cell Metab 17: 210-224.

33. Warner DR, Horn KH, Mudd L, Webb CL, Greene RM, et al. (2007) PRDM16/MEL1: a novel Smad binding protein expressed in murine embryonic orofacial tissue. Biochim Biophys Acta 1773: 814-820.

34. Yadav H, Quijano C, Kamaraju AK, Gavrilova O, Malek R, et al. (2011) Protection from obesity and diabetes by blockade of TGF-beta/Smad3 signaling. Cell Metab 14: 67-79.
35. Herron BJ, Lu W, Rao C, Liu S, Peters H, et al. (2002) Efficient generation and mapping of recessive developmental mutations using ENU mutagenesis. Nat Genet 30: 185-189.

36. Bjork BC, Vieira AR, Faust S, Camper SA, Murray JC, et al. (2006) Phenotypic, Genetic, and Developmental Characterization of CPO1, a Recessive ENU-induced Mouse Model of Cleft Palate. Mouse Molecular Genetics Cold Spring Harbor Press, Woodbury, NY.

37. Bjork BC, Turbe-Doan A, Prysak M, Herron BJ, Beier DR (2010) Prdm16 is required for normal palatogenesis in mice. Hum Mol Genet 19: 774-789.

38. Ding HL, Clouthier DE, Artinger KB (2013) Redundant roles of PRDM family members in zebrafish craniofacial development. Dev Dyn 242: 67-79.

39. Warner DR, Mukhopadhyay P, Webb CL, Greene RM, Pisano MM (2012) Chromatin immunoprecipitation-promoter microarray identification of genes regulated by PRDM16 in murine embryonic palate mesenchymal cells. Exp Biol Med (Maywood) 237: 387-394.

40. Warner DR, Wells JP, Greene RM, Pisano MM (2013) Gene expression changes in the secondary palate and mandible of Prdm16(-/-) mice. Cell Tissue Res 351: 445-452.

41. Horn KH, Warner DR, Pisano M, Greene RM (2011) PRDM16 expression in the developing mouse embryo. Acta Histochem 113: 150-155.

42. Derecka M, Gornicka A, Koralov SB, Szczepanek K, Morgan M, et al. (2012) Tyk2 and Stat 3 regulate brown adipose tissue differentiation and obesity. Cell Metab 16: 814-824.

43. Gewies A, Castineiras-Vilarino M, Ferch U, Jahrling N, Heinrich K, et al. (2013) Prdm6 is essential for cardiovascular development in vivo. PLoS One 8: e81833.

44. Bogani D, Morgan MA, Nelson AC, Costello I, McGouran JF, et al. (2013) The PR/SET domain zinc finger protein Prdm4 regulates gene expression in embryonic stem cells but plays a nonessential role in the developing mouse embryo. Mol Cell Biol 33: 3936-3950.

45. Hohenauer T, Moore AW (2012) The Prdm family: expanding roles in stem cells and development. Development 139: 2267-2282.

46. Yang CM, Shinkai Y (2013) Prdm12 is induced by retinoic acid and exhibits anti-proliferative properties through the cell cycle modulation of P19 embryonic carcinoma cells. Cell Struct Funct 38: 195-204.

47. Galli GG, Honnens de Lichtenberg K, Carrara M, Hans W, Wuelling M, et al. (2012) Prdm5 regulates collagen gene transcription by association with RNA polymerase II in developing bone. PLoS Genet 8: e1002711. 